\title{
Improve Patient Safety Practices in the Out Patient Department of Oral Health Care Clinics;
}

\section{A Case Study: The Regional Director of Health Services in Badulla District; Sri Lanka}

\author{
Y.M.S.S. Yapa ${ }^{1 *}$, S.N. Kumari², S.R. Jayasinghe², T.H.N.G. Amaraweera ${ }^{3}$ \\ ${ }^{1}$ Postgraduate Institute of Medicine, University of Colombo \\ ${ }^{2}$ Department of Science and Technology, Faculty of Applied Sciences, Uva Wellassa University, Badulla, Sri Lanka. \\ ${ }^{3}$ Department of Applied Earth Sciences, Faculty of Applied Sciences, Uva Wellassa University, Badulla, Sri Lanka. \\ DOI: 10.29322/IJSRP.11.06.2021.p11452 \\ http://dx.doi.org/10.29322/IJSRP.11.06.2021.p11452
}

\begin{abstract}
Patient safety practices in the Out-Patient Department (OPD) of oral health care clinics are not adequately in place in the public health care delivery system in Sri Lanka due to a lack of understating of patient safety practices in dentistry. Further, the low quality of record-keeping may imply the underestimation of patient safety in oral health care treatment. The present study was carried out as an interventional research project to improve patient safety practices in the OPD of oral health care clinics under the Regional Director of Health Services in Badulla District (RDHS-Badulla District). Patient safety practices were assessed by self-administered questionnaires during the pre-interventional stage. Gaps have been identified after analyzing the results of pre-intervention, which were used to design the intervention. Two "One Day" workshops were conducted to make awareness to improve patient safety practices. The new system was allowed to be in practice for four months and thereafter the post-assessment of the effect of the interventions was assessed during post-interventional. This study provides an insight into the enhancement of safety practices of the oral healthcare system in RDHS-Badulla District. It shows the improvement of awareness regarding safety, adverse events reporting, availability of dental safety checklist after the intervention. Continuous supervision and training regarding patient safety and national-level policy are recommended for the sustainability of the project.
\end{abstract}

Index Terms- Oral Health Care Clinics, Sri Lanka, Outpatient Department, Patient Safety Practices,

\section{INTRODUCTION}

In oral healthcare, patient safety has not received explicit attention due to a lack of conceptual understating of patient safety in dentistry (Bailey et al. 2015). Further, primary oral health care is considered safe to the patient due to a low incidence of adverse events and the absence of major harm to the patient Bailey et al. 2015. Many of the oral health care clinics are unstructured and the dentists may not be aware of the occurrence of adverse events (Yamalik \& Pe'rez, 2012). Low quality of record-keeping may also imply the underestimation of patient safety in oral health care treatment (Mettes et al. 2013).

Jadhav et al. (2016) reported that the safety culture in dentistry can be developed by commitment, routine audits and risk assessment of hazards, safe practices and continuing educational activities for staff. Identification of errors and the cause of adverse events in oral treatment is the first step towards dental patient safety (Obadan et al. 2015). In Sweden, recording adverse events is mandatory and identified as an effective way of dealing with patient safety (Jonsson and Gabre, 2014). Further, several studies have shown that the introduction of a checklist helped to prevent the wrong tooth extraction and avoid misdiagnosis (Saksena et al., 2014, Beddis et al., 2014, Arriaga et al. 2013).

Sri Lanka is a developing country with a lack of concern for patient safety. The study implied that the prevailing safety culture of tertiary health care hospital in Sri Lanka in a reactive stage with strong blame culture and adverse event reporting is very low due to fear of blame and punishment (Amarapathy et al. 2013, Liyanagamage \& Saranasinghe, 2017, Issadeen \& Issadeen, A. (2019). Further, blame culture may lead to non-identification of errors and affect the learning culture (Liyanagamage \& Saranasinghe, 2017). Shortage of staff, leadership, lack of confidence in management and supervision, ineffective communication and work environment significantly affect the patient safety programme in Government hospitals of Sri Lanka (Sridharan et al. 2017). 
Minimizing the communication gap and promoting teamwork will also help to build patient safety culture (Amarapathy et al. 2013). Moreover, it is necessary to provide more learning opportunities for health care staff to improve patient safety. Compared to the general health care system, patient safety in dentistry in Sri Lanka is in its primitive stages. Hence, assessment of quality and safety associated factors in the oral health care system in Sri Lanka will help to improve the health care quality and establish a patient safety culture in the future.

The health care system of Sri Lanka has followed the National Guidelines for the improvement of the quality and safety of the Health Care Institute since 2010 (Ministry of Health, $2010(\mathrm{a}, \mathrm{b})$ ). This guideline focused on three major aspects, 01) internal and external customer environment, 02) service involving patient contact and 03) overall quality control and safety improvement. Overall quality control and safety improvement guideline include infection control, waste management, medical records, health education activities, etc.

The public oral health care services are provided to the people through the Ministry of Health, Sri Lanka and it is free of charge at the point of delivery. According to the oral health unit, Ministry of Health Sri Lanka, 1536 dental surgeons were working in the public sector in the year 2016 (National Oral Health Survey Sri Lanka, 2015-2016).

According to the Annual Health Statistics in 2016, out of 2,777,904 patients who attended treatment from the OPD oral health care clinics, 836,425 patients received dental extraction and 21,151 underwent minor oral surgery in Sir Lanka (Ministry of Healthcare and Nutrition, 2018). It showed that 234,630 of the patients who had undergone oral health care treatment from public oral health care units in the Badulla district, 66256 of the patients had undergone teeth extractions and 1884 had undergone minor surgeries in 2016. (Ministry of Healthcare and Nutrition, 2018). Although there is a large volume of epidemiological data available regarding medical errors, mistakes and adverse events in the hospital setting, data relating to dentistry are uncommon.

Patient safety practices in OPD oral health care clinics are not adequately in place in the public health care delivery system in Sri Lanka. Hence, patient safety practices need to be developed and introduced to the public oral health care system. To assess the current patient safety practices in the OPD oral health care clinics under the RDHS-Badulla District are considered.

\section{METHODOLOGY}

An interventional research project was conducted among all dentists OPD oral health care clinics $(\mathrm{N}=42)$ under the RDHS-Badulla District. A new Self-Administered Questionnaire (SAQ) was based on the Hospital Survey on Patient Safety Culture questionnaire, which was developed by the Agency for Healthcare Research and Quality (Sorra et al. 2018). Ethical clearance for conduct the research project was obtained from the Ethical Committee of Postgraduate Institute of Medicine Colombo. Written consent from the relevant authorities of the hospitals was taken before the intervention. Privacy was ensured during the data collection. Administrative clearance for data collection was obtained from the Provincial Director of Health Services in Uva province, the RDHS and RDS in Badulla District.

A project was conducted in three (03) stages, i.e. pre-interventional, interventional and post-interventional The pre-tested SAQ was used as a quantitative method to achieve specific objectives for all oral health care clinics under the RDHS Badulla. Gaps identified by the above discussions and questionnaires were further discussed with the medical administrators, RDS and dental surgeons. Strategies were identified to achieve better patient safety practices. Further, the training/workshop plan was prepared to operationalize the strategies. This training/workshop plan was forwarded to relevant authorities in the hospitals and formal approval for implementation was obtained.

Two "One Day" workshops for the dental surgeons under the RDHS-Badulla District were conducted after analyzing the results of a SAQ. Those workshops were conducted to improve awareness of dental surgeons' about the errors and patient safety and safety of the health care system. Further, workshops aim to improve the availability of emergency medicine trays, a safety checklist and reporting system of the OPD oral health clinics. Experts introduced locally adopted dental safety checklist (Annexure 1), incident, accident, errors, mistakes, adverse events reporting system (Annexure 1), emergency medicine tray, etc.

The results of pre-intervention and post-intervention were assessed to evaluate improve the patient safety practices in the OPD oral health care clinics under the Regional Director of Health Services in Badulla District (RDHS-Badulla District).

Quantitative data analysis was carried out using a statistical software application (SPSS- Version 22). McNemar's test and paired t-test were performed to assess the significance of pre and post-interventional results. Qualitative data was analyzed after coding and grouping according to common themes.

Methods: For every question which was used to measure OPD oral health care safety practices in the questionnaire and frequency tables were created for pre and post-assessment. Two samples were collected pre and post-assessment from the same group of individuals

This publication is licensed under Creative Commons Attribution CC BY.

http://dx.doi.org/10.29322/IJSRP.11.06.2021.p11452

www.ijsrp.org 
which are considered as the dependent samples. Therefore, to evaluate the effectiveness of the programme statistically, McNemar's test was performed for each question. All the variables which had more than two categories were reduced to two categories by amalgamating original categories. Then by creating $2 \times 2$ contingency tables, McNemar's test was performed.

The null and alternative hypothesis is stated as below.

H1: There is no impact from the intervention Vs H1: There is an impact from the intervention

\section{RESULTS AND DISCUSSION}

\section{A. Socio-demographic factors of the participants}

Among 42 dentists at RDHS-Badulla, the response rate of $85.7 \%$ reported in this study was comparable with a study on patient safety culture perceptions in dentistry (72.8\%) in Saudi Arabia (Al Sweleh et al. 2018). The majority of the clinic are located in rural areas $(72.2 \%)$. More than $50 \%$ of the staff members have working experience for more than 2 years (Table 1 ).

Table 1. Dental Surgeon Survey on Patient Safety Culture: Participant Description

\begin{tabular}{lc}
\hline & Frequency (Percentage \%) \\
\hline Gender (N=36) & \\
Male & $15(41.7 \%)$ \\
Female & $21(58.3 \%)$ \\
\hline Practice Location (N=36) & \\
Rural & $26(72.2 \%)$ \\
Urban & $10(27.8 \%)$ \\
\hline Practice Type $(\mathbf{N}=\mathbf{3 6})$ & \\
Solo Practitioner & $21(58.3 \%)$ \\
Multiple Practitioner & $15(41.7 \%)$ \\
\hline Experience $(\mathbf{N = 3 6})$ & \\
$<=1$ yr & $5(13.9 \%)$ \\
$2-5$ yrs & $20(55.6 \%)$ \\
$6-10$ yrs & $1(2.8 \%)$ \\
$>=11$ yrs & $10(27.8 \%)$ \\
\hline
\end{tabular}

\section{B. Awareness of staff about the error and patient safety}

Awareness of the staff about the error and patient safety was assessed using McNemar's test before and after the intervention (Table 2). All p-values of McNemar's test done from "a to g questions on awareness are less than a 5\% significance level. Therefore, there is a positive impact from intervention on the awareness of dentists about the error and patient safety.

Table 2: Results of McNemar's test on awareness of staff about the error and patient safety (under 7 categories)

\begin{tabular}{|c|c|c|c|c|c|c|c|}
\hline & \multicolumn{3}{|c|}{ McNemar's test } & & \multicolumn{3}{|c|}{ McNemar's test } \\
\hline & High & Low & P-value & & High & Low & P-value \\
\hline \multicolumn{4}{|c|}{ a. Different types of human error? } & \multicolumn{4}{|c|}{ b. A factor contributing to human error? } \\
\hline Before $(\mathrm{N}=36)$ & 2 & 34 & \multirow[t]{2}{*}{0.000} & Before $(\mathrm{N}=36)$ & 4 & 32 & \multirow[t]{2}{*}{0.000} \\
\hline After(N=36) & 24 & 12 & & After(N=36) & 31 & 5 & \\
\hline \multicolumn{4}{|c|}{ c. Factors influencing patient safety? } & \multicolumn{4}{|c|}{ d.Ways of speaking up about error? } \\
\hline Before $(\mathrm{N}=36)$ & 15 & 22 & \multirow[t]{2}{*}{0.031} & Before $(\mathrm{N}=36)$ & 8 & 28 & \multirow[t]{2}{*}{0.000} \\
\hline After(N=36) & 30 & 6 & & After(N=36) & 9 & 27 & \\
\hline \multicolumn{4}{|c|}{ e. What should happen if an error is made? } & \multicolumn{4}{|c|}{ f. How to report an error? } \\
\hline Before $(\mathrm{N}=36)$ & 5 & 31 & \multirow[t]{2}{*}{0.001} & Before $(\mathrm{N}=36)$ & 1 & 35 & \multirow[t]{2}{*}{0.000} \\
\hline After(N=36) & 11 & 25 & & After(N=36) & 26 & 10 & \\
\hline \multicolumn{4}{|c|}{ g.The role of healthcare organizations in error reporting? } & & & & \\
\hline Before $(\mathrm{N}=36)$ & 4 & 32 & \multirow[t]{2}{*}{0.000} & & & & \\
\hline After(N=36) & 15 & 21 & & & & & \\
\hline
\end{tabular}


Compare the overall awareness of staff before and after the intervention, the paired t-test was applied (Table 3). According to the analysis, the average percentage score was increased after the intervention. Further test results confirmed that there is an effect from the intervention on the awareness of staff about the error and patient safety since the p-value is less than a 5\% significance level.

Table 3: Overall awareness of staff about the error and patient safety

\begin{tabular}{llllll}
\hline & Mean & Standard Deviation & Difference & t-test & p-value \\
\hline Before & 48.81 & 19.13 & 12.70 & -3.37 & \multirow{2}{*}{0.001} \\
After & 61.51 & 14.01 & & \\
\hline
\end{tabular}

\section{Awareness of the Dentists about the safety of the healthcare system}

Awareness of the dentists about the safety of the healthcare system was measured under 5 likert scale and results before and after the intervention were given in Table 4. Except for the " Healthcare staff receive training in patient safety", all other measures are significant, Hence, it can be indicated that there is a positive impact from the intervention on awareness of the dentists about the safety of the healthcare system.

Table 4: Results of McNemar's test on Awareness about Safety of the Healthcare System under six measures

\begin{tabular}{|c|c|c|c|c|c|c|c|c|}
\hline \multirow{2}{*}{ Measures } & \multicolumn{5}{|c|}{ Observed frequencies under 5-likert-scale } & \multicolumn{3}{|c|}{ McNemar's test } \\
\hline & $\begin{array}{l}\text { Strongly } \\
\text { Disagree }\end{array}$ & Disagree & Neutral & Agree & $\begin{array}{l}\text { Strongly } \\
\text { Agree }\end{array}$ & High & Low & P-value \\
\hline \multicolumn{9}{|c|}{ a.Most healthcare workers make errors } \\
\hline Before $(\mathrm{N}=36)$ & 1 & 17 & 9 & 9 & 0 & 18 & 18 & \multirow[t]{2}{*}{0.000} \\
\hline After $(\mathrm{N}=36)$ & 0 & 0 & 1 & 31 & 4 & 36 & 0 & \\
\hline \multicolumn{9}{|c|}{ b.In my country, there is a safe system of healthcare for patients } \\
\hline Before $(\mathrm{N}=36)$ & 2 & 6 & 10 & 18 & 0 & 28 & 8 & \multirow[t]{2}{*}{0.008} \\
\hline After $(\mathrm{N}=36)$ & 0 & 0 & 10 & 25 & 1 & 36 & 0 & \\
\hline \multicolumn{9}{|c|}{ c.Medical error is very common } \\
\hline Before $(\mathrm{N}=36)$ & 3 & 14 & 14 & 4 & 1 & 19 & 17 & \multirow[t]{2}{*}{0.000} \\
\hline After(N=36) & 0 & 1 & 8 & 23 & 4 & 35 & 1 & \\
\hline \multicolumn{9}{|c|}{ d.It is very unusual for patients to be given the wrong drug } \\
\hline Before $(\mathrm{N}=36)$ & 3 & 2 & 9 & 18 & 4 & 31 & 5 & \multirow[t]{2}{*}{0.000} \\
\hline After(N=36) & 2 & 24 & 4 & 6 & 0 & 10 & 26 & \\
\hline \multicolumn{9}{|c|}{ e.Healthcare staff receive training in patient safety } \\
\hline Before $(\mathrm{N}=36)$ & 0 & 4 & 10 & 22 & 0 & 32 & 4 & \multirow[t]{2}{*}{0.375} \\
\hline After(N=36) & 0 & 1 & 13 & 18 & 4 & 35 & 1 & \\
\hline \multicolumn{9}{|c|}{ f.About one in ten hospital patients across the world will experience some kind of adverse event } \\
\hline Before $(\mathrm{N}=36)$ & 0 & 6 & 18 & 11 & 1 & 30 & 6 & \multirow[t]{2}{*}{0.031} \\
\hline After(N=36) & 0 & 0 & 18 & 8 & 10 & 36 & 0 & \\
\hline
\end{tabular}

Compare the overall awareness of dentists about the safety of the healthcare system before and after the intervention, the paired-t test was applied (Table 5). According to the analysis, the average percentage score was increased after the intervention. Further, test results confirmed that there is an effect from the programme on awareness about the safety of the healthcare system since the p-value is less than a $5 \%$ significance level.

Table 5: Overall awareness about the safety of the healthcare system

\begin{tabular}{llllll}
\hline & Mean & Standard Deviation & Difference & t-test & p-value \\
\hline Before & 50.93 & 27.87 & 14.35 & -244 & \multirow{2}{*}{0.010} \\
After & 65.29 & 20.85 & & & \\
\hline
\end{tabular}

This publication is licensed under Creative Commons Attribution CC BY. 


\section{Assessing Patient Safety Practices in the OPD Oral Healthcare Clinics}

The available facilities, procedures and support of staff at the work area to adhere to the safety practices were evaluated using thirteen measures in Table 6 before and after the intervention. Among all the measures, $\mathrm{b}$, $\mathrm{i}$ and $\mathrm{k}$ are significant according to the $\mathrm{p}$ values of McNemar's test and remaining measures are not significant.

Table 6: Frequencies and McNemar's test results on Patient safety practices in OPD oral healthcare clinics in the work area

\begin{tabular}{|c|c|c|c|c|c|c|c|c|}
\hline \multirow[t]{2}{*}{ Measures } & \multicolumn{5}{|c|}{ Observed frequencies under 5-likert-scale } & \multicolumn{3}{|c|}{ McNemar's test } \\
\hline & $\begin{array}{l}\text { Strongly } \\
\text { Disagree }\end{array}$ & Disagree & Neutral & Agree & $\begin{array}{l}\text { Strongly } \\
\text { Agree }\end{array}$ & Agree & Disagree & P-value \\
\hline \multicolumn{9}{|c|}{ a.People support one another in this unit } \\
\hline Before $(\mathrm{N}=36)$ & 0 & 2 & 3 & 27 & 4 & 34 & 2 & \multirow[t]{2}{*}{0.500} \\
\hline After $(\mathrm{N}=36)$ & 0 & 0 & 0 & 32 & 4 & 36 & 0 & \\
\hline \multicolumn{9}{|c|}{ b.We have enough staff to handle the workload } \\
\hline Before $(\mathrm{N}=36)$ & 4 & 19 & 4 & 9 & 0 & 13 & 23 & \multirow[t]{2}{*}{0.003} \\
\hline After $(\mathrm{N}=36)$ & 0 & 9 & 2 & 24 & 1 & 27 & 9 & \\
\hline \multicolumn{9}{|c|}{ c.When a lot of work needs to be done quickly, we work together as a team to get the work done } \\
\hline Before $(\mathrm{N}=36)$ & 0 & 3 & 4 & 28 & 1 & 33 & 3 & \multirow[t]{2}{*}{0.625} \\
\hline After $(\mathrm{N}=36)$ & 0 & 1 & 1 & 33 & 1 & 35 & 1 & \\
\hline \multicolumn{9}{|c|}{ d.In this unit, people treat each other with respect } \\
\hline Before $(\mathrm{N}=36)$ & 0 & 2 & 1 & 27 & 6 & 34 & 2 & \multirow[t]{2}{*}{1.000} \\
\hline After $(\mathrm{N}=36)$ & 0 & 2 & 1 & 22 & 11 & 36 & 0 & \\
\hline \multicolumn{9}{|c|}{ e.We are actively doing things to improve patient safety } \\
\hline Before $(\mathrm{N}=36)$ & 0 & 2 & 6 & 28 & 0 & 34 & 2 & \multirow[t]{2}{*}{0.500} \\
\hline After $(\mathrm{N}=36)$ & 0 & 0 & 1 & 34 & 1 & 34 & 2 & \\
\hline \multicolumn{9}{|c|}{ f.The staff feel like their mistakes are held against them } \\
\hline Before $(\mathrm{N}=36)$ & 1 & 9 & 14 & 12 & 0 & 26 & 10 & \multirow[t]{2}{*}{0.263} \\
\hline After $(\mathrm{N}=36)$ & 0 & 16 & 4 & 16 & & 20 & 16 & \\
\hline \multicolumn{9}{|c|}{ g.Mistakes have led to positive changes here } \\
\hline Before $(\mathrm{N}=36)$ & 0 & 1 & 16 & 19 & 0 & 35 & 1 & \multirow[t]{2}{*}{1.000} \\
\hline After $(\mathrm{N}=36)$ & 0 & 0 & 0 & 36 & 0 & 34 & 2 & \\
\hline \multicolumn{9}{|c|}{ h.It is just by chance that more serious mistakes don't happen around here } \\
\hline Before $(\mathrm{N}=36)$ & 1 & 5 & 9 & 21 & 0 & 30 & 6 & \multirow[t]{2}{*}{0.289} \\
\hline After $(\mathrm{N}=36)$ & 0 & 2 & 5 & 29 & 0 & 34 & 2 & \\
\hline \multicolumn{9}{|c|}{ i.After we make changes to improve patient safety, we evaluate their effectiveness } \\
\hline Before $(\mathrm{N}=36)$ & 0 & 11 & 8 & 15 & 2 & 25 & 11 & \multirow[t]{2}{*}{0.006} \\
\hline After $(\mathrm{N}=36)$ & 0 & 1 & 20 & 14 & 1 & 35 & 1 & \\
\hline \multicolumn{9}{|c|}{ j.Patient safety is never sacrificed to get more work done } \\
\hline Before $(\mathrm{N}=36)$ & 1 & 2 & 10 & 20 & 3 & 33 & 3 & \multirow[t]{2}{*}{0.250} \\
\hline After $(\mathrm{N}=36)$ & 0 & 0 & 6 & 27 & 3 & 36 & 0 & \\
\hline \multicolumn{9}{|c|}{ k.Staff worry that mistakes they make are kept in their personnel file } \\
\hline Before $(\mathrm{N}=36)$ & 1 & 6 & 6 & 22 & 0 & 28 & 7 & 0.016 \\
\hline After $(\mathrm{N}=36)$ & 0 & 0 & 8 & 28 & 0 & 34 & 0 & \\
\hline 1.We have patie & afety proble & s in this un & & & & & & \\
\hline Before $(\mathrm{N}=36)$ & 1 & 11 & 12 & 11 & 1 & 24 & 12 & 1.000 \\
\hline After(N=36) & 0 & 13 & 18 & 5 & 0 & 23 & 13 & \\
\hline m.Our procedur & nd systems & re good at & eventing $\mathrm{e}$ & ors from & appening & & & \\
\hline Before $(\mathrm{N}=36)$ & 0 & 7 & 13 & 16 & 0 & 29 & 7 & 1.000 \\
\hline After(N=36) & 0 & 6 & 6 & 24 & 0 & 30 & 6 & \\
\hline
\end{tabular}


The supervisor's involvement in safety practices was analyzed before and after the intervention under three categories and results are shown in Table 7. Among all the categories, a and c are significant according to the p-values of Mcnemar's test.

Table 7: Patient Safety Practices in the OPD Oral Healthcare Clinics - Supervisor

\begin{tabular}{|l|c|c|c|c|c|c|c|c|}
\hline \multirow{2}{*}{ Measures } & \multicolumn{6}{|c|}{ Observed frequencies under 5-likert-scale } & \multicolumn{3}{c|}{ McNemar's test } \\
\cline { 2 - 8 } & $\begin{array}{c}\text { Strongly } \\
\text { Disagree }\end{array}$ & Disagree & Neutral & Agree & $\begin{array}{c}\text { Strongly } \\
\text { Agree }\end{array}$ & Agree & Disagree & P-value \\
\hline a.the supervisor says a good word when he/she see a job done according to established patient safety procedures \\
\hline Before(N=36) & 0 & 7 & 14 & 15 & 0 & 29 & 7 & 0.016 \\
\hline After(N=36) & 0 & 0 & 15 & 18 & 3 & 36 & 0 \\
\hline b.My supervisor/manager seriously considers staff suggestions for improving patient safety \\
\hline Before(N=36) & 0 & 3 & 14 & 19 & 0 & 33 & 3 & 0.250 \\
\hline After (N=36) & 0 & 0 & 9 & 27 & 0 & 36 & 0 \\
\hline c.Whenever pressure builds up, my supervisor wants us to work faster, even if it means taking shortcuts \\
\hline Before(N=36)
\end{tabular}

Table 8 summarizes the frequency of events reported in before and after the intervention under two measures. According to the results, it can be identified that the reporting frequency of events increases after the intervention. Further, it was proven statistically using a McNemar's test.

Table 8: Patient safety practices in OPD oral healthcare clinics - Frequency of event reported

\begin{tabular}{|c|c|c|c|c|c|c|c|c|}
\hline \multirow[t]{2}{*}{ Measures } & \multicolumn{5}{|c|}{ Observed frequencies under 5-likert-scale } & \multicolumn{3}{|c|}{ McNemar's test } \\
\hline & Never & Rarely & $\begin{array}{l}\text { Some } \\
\text { Times }\end{array}$ & $\begin{array}{l}\text { Most of } \\
\text { the time }\end{array}$ & Always & $\begin{array}{l}\text { Most of } \\
\text { the time }\end{array}$ & Rarely & P-value \\
\hline \multicolumn{9}{|c|}{ a.When a mistake is made but is caught and corrected before affecting the patient, how often is this reported? } \\
\hline Before $(\mathrm{N}=36)$ & 9 & 17 & 2 & 6 & 2 & 8 & 28 & \multirow[t]{2}{*}{0.000} \\
\hline After(N=36) & 1 & 0 & 11 & 24 & 0 & 24 & 12 & \\
\hline \multicolumn{9}{|c|}{ b.When a mistake is made but has no potential to harm the patient, how often is this reported? } \\
\hline Before $(\mathrm{N}=36)$ & 13 & 13 & 2 & 5 & 3 & 8 & 28 & \multirow[t]{2}{*}{0.000} \\
\hline After(N=36) & 0 & 5 & 12 & 10 & 9 & 19 & 17 & \\
\hline
\end{tabular}

Lack of conceptual understating of patient safety in dentistry has been identified as a major problem for lack of attention for patient safety (Bailey et al. 2015). Several studies reported that the educational activities for staff as a key factor to improve patient safety in dentistry (Yamalik and Perea-Pe'rez, 2012; Jadhav et al. 2016). Mahar et al. (2012) reported in their systematic review imply the use of a specific educational intervention, targeting junior dental staff using a training session led to improve patient safety. Similarly, the current study showed a positive effect on the awareness of the staff about the errors and patient safety $(\mathrm{p}=0.001)$ and the safety of the oral healthcare system $(\mathrm{p}=0.010)$ after the intervention.

\section{E. Awareness of staff about the error and patient safety Use of dental safety checklist and patient health recording system}

Table 9 summarized the assessment of the use of the dental safety checklist and patient health recording system. Results of McNemar's test revealed that the availability of the dental safety checklist $(\mathrm{p}=0.008)$ improved significantly after the intervention. But usage of dental safety checklist during the extraction/ minor oral surgical procedures improved $5.55 \%$ and showed statistically insignificantly after the intervention $(\mathrm{p}=0.500)$.

The study shows that the availability of the patient history recording system and record maintaining system improved quantitatively after the intervention even though improvements are statistically insignificant ( $\mathrm{p}>0.05)$. However, McNemar's test shows that errors, mistakes, adverse events, near misses reporting system $(\mathrm{p}=0.001)$ improved in the oral health care system after the intervention.

This publication is licensed under Creative Commons Attribution CC BY. 
However, Open discussion regarding errors, mistakes, adverse effects improved quantitatively after the intervention. But the improvement is statistically insignificant $(\mathrm{p}=0.063)$.

Table 9: Surgical Safety Checklist and Patient Health Recording System

\begin{tabular}{|c|c|c|c|c|c|c|c|c|c|}
\hline \multirow{3}{*}{ Measurements } & \multicolumn{4}{|c|}{ Frequencies } & \multirow{3}{*}{\multicolumn{2}{|c|}{ Categories }} & \multicolumn{3}{|c|}{ McNemar's test } \\
\hline & \multicolumn{2}{|c|}{ Before } & \multicolumn{2}{|c|}{ After } & & & \multicolumn{2}{|c|}{ After } & \multirow{2}{*}{ P-value } \\
\hline & 0 & 1 & 0 & 1 & & & 0 & 1 & \\
\hline \multicolumn{10}{|l|}{ Surgical Safety Checklist } \\
\hline \multirow{2}{*}{$\begin{array}{l}\text { Availability of dental safety } \\
\text { checklist }\end{array}$} & \multirow{2}{*}{36} & \multirow{2}{*}{0} & \multirow{2}{*}{28} & \multirow{2}{*}{8} & \multirow{2}{*}{ Before } & 0 & 28 & 8 & \multirow{2}{*}{0.008} \\
\hline & & & & & & 1 & 0 & 0 & \\
\hline \multirow{2}{*}{$\begin{array}{l}\text { Using of dental safety checklist } \\
\text { when the extraction/ minor oral } \\
\text { surgical procedures }\end{array}$} & \multirow{2}{*}{36} & \multirow{2}{*}{0} & \multirow{2}{*}{34} & \multirow{2}{*}{2} & \multirow{2}{*}{ Before } & 0 & 34 & 2 & \multirow{2}{*}{0.500} \\
\hline & & & & & & 1 & 0 & 0 & \\
\hline \multicolumn{10}{|c|}{ Patient Health Recording System (Errors, Mistakes And Adverse Events, Complains) } \\
\hline \multirow{2}{*}{$\begin{array}{l}\text { a. Availability of patient history } \\
\text { recording system }\end{array}$} & \multirow{2}{*}{26} & \multirow{2}{*}{10} & \multirow{2}{*}{21} & \multirow{2}{*}{15} & \multirow{2}{*}{ Before } & 0 & 21 & 5 & \multirow{2}{*}{0.063} \\
\hline & & & & & & 1 & 0 & 10 & \\
\hline \multirow[t]{2}{*}{ b. Record maintaining system } & \multirow{2}{*}{31} & \multirow{2}{*}{5} & \multirow{2}{*}{26} & \multirow{2}{*}{10} & Before & 0 & 26 & 5 & 0063 \\
\hline & & & & & Derore & 1 & 0 & 5 & $0.00 J$ \\
\hline c. Errors, mistake, adverse events, & 32 & 4 & 21 & 15 & Before & 0 & 21 & 11 & 0001 \\
\hline near misses reporting system & & & & & & 1 & 0 & 4 & \\
\hline d. Open discussion regarding errors, & 36 & 0 & 31 & 5 & Before & 0 & 31 & 5 & 0063 \\
\hline mistakes, adverse effects & (3) & & & & Delore & 1 & 0 & 0 & 0.005 \\
\hline
\end{tabular}

Recording adverse events and communicating lessons learned from the adverse events have been identified as an effective method to improve safety in the oral health care system (Jonsson \& Gabre, 2014; Pemberton, 2014 Perea-Pérez et al.; 2011,2014,). The current study implied the positive impact on the frequency of errors, mistake, adverse events reporting system after the intervention ( $\mathrm{p}=0.001)$. Liyanagamage \& Saranasinghe (2017), reported that the blame culture may lead to non-identification of errors and affect the learning culture in the health care system in Sri Lanka. This may be one of the reasons for the low level of open discussion regarding errors, mistakes, adverse effects among the dentist in RDHS-Badulla ( $\mathrm{p}=0.063)$.

Several studies have shown that the introduction of a checklist policy helped to prevent the wrong tooth extraction (Beddis et al. 2014; Saksena et al. 2014). Arriaga et al. (2013) described a 75\% reduction in omission errors with the use of a checklist. Similarly, the present study revealed the increase in the availability of dental safety checklist after the intervention $(\mathrm{p}=0.008)$. This might be positively affected by patient safety practices. However, the level of adapting dental safety checklist was not satisfactory due to over-crowding of patients, reluctant to documentation and overconfidence of the dentists.

\section{F. Patient safety practices}

Pre-intervention clearly shows the usage of personnel protective methods, sterilization and disinfection procedures and waste management practices are well established among all studied dental clinics in the Badulla District. Summary of results and significant test outputs are summarized in Table 10 to Table 12. Measurements of $f$ and $g$ under personal protective methods are only significantly different at 5\% level while other measurements do not have any influence for before and after the intervention. Further, $d$ and e measuremnts under Sterilization and Disinfection Procedures and d measurement under Waste Management Practices are significantly different at $10 \%$ level even though, there is no impact from all other measurements for before and after the intervention. 
Table 10: Frequencies and McNemar's test results of Personnel Protective Methods

\begin{tabular}{|c|c|c|c|c|c|c|c|c|c|}
\hline \multirow{2}{*}{ Measurements on Personnel Protective Methods } & \multicolumn{2}{|c|}{ Before } & \multicolumn{2}{|c|}{ After } & \multirow{2}{*}{\multicolumn{2}{|c|}{ Categories }} & \multicolumn{2}{|c|}{ After } & \multirow{2}{*}{$P$-value } \\
\hline & 0 & 1 & 0 & 1 & & & 0 & 1 & \\
\hline \multirow{2}{*}{ a.Agent used for cleaning hand } & \multirow{2}{*}{31} & \multirow{2}{*}{5} & \multirow{2}{*}{25} & \multirow{2}{*}{11} & \multirow{2}{*}{ Before } & 0 & 21 & 10 & \multirow{2}{*}{0.180} \\
\hline & & & & & & 1 & 4 & 1 & \\
\hline \multirow{2}{*}{ b.Disposable gloves use in each and every procedure } & \multirow{2}{*}{11} & \multirow{2}{*}{25} & \multirow{2}{*}{6} & \multirow{2}{*}{30} & \multirow{2}{*}{ Before } & 0 & 1 & 10 & \multirow{2}{*}{0.302} \\
\hline & & & & & & 1 & 5 & 20 & \\
\hline \multirow{2}{*}{ c.Wearing of face mask in patient examination \& treatment } & \multirow{2}{*}{36} & \multirow{2}{*}{0} & \multirow{2}{*}{36} & \multirow{2}{*}{0} & \multirow{2}{*}{ Before } & 0 & 0 & 0 & \multirow{2}{*}{ NA } \\
\hline & & & & & & 1 & 36 & 0 & \\
\hline \multirow{2}{*}{$\begin{array}{l}\text { d.Wearing of protective gowns, aprons when the treatment } \\
\text { process }\end{array}$} & \multirow{2}{*}{22} & \multirow{2}{*}{14} & \multirow{2}{*}{17} & \multirow{2}{*}{19} & \multirow{2}{*}{ Before } & 0 & 11 & 11 & \multirow{2}{*}{0.332} \\
\hline & & & & & & 1 & 6 & 8 & \\
\hline \multirow{2}{*}{ e.Wearing of goggles / eye protection in treatment procedures } & \multirow{2}{*}{36} & 0 & 36 & 0 & Before & 0 & 36 & 0 & NA \\
\hline & & & & & & 1 & 0 & 0 & \\
\hline f.For each patient prepare a new tray & 14 & 22 & 2 & 34 & Before & 0 & 0 & 14 & 0.004 \\
\hline & 14 & 22 & 2 & 34 & Berore & 1 & 2 & 20 & 0.004 \\
\hline g.Safety of high speed hand instruments & 14 & 22 & 4 & 32 & Before & 0 & 3 & 11 & 0006 \\
\hline & & & & & & 1 & 1 & 21 & 0.006 \\
\hline
\end{tabular}

Table 11: Frequencies and McNemar's test results of Sterilization and Disinfection Procedures

\begin{tabular}{|c|c|c|c|c|c|c|c|c|c|}
\hline \multirow{2}{*}{ Measurements on Sterilization and Disinfection Procedures } & \multicolumn{2}{|c|}{ Before } & \multicolumn{2}{|c|}{ After } & \multirow{2}{*}{\multicolumn{2}{|c|}{ Categories }} & \multicolumn{2}{|c|}{ After } & \multirow{2}{*}{ P-value } \\
\hline & 0 & 1 & 0 & 1 & & & 0 & 1 & \\
\hline \multirow{2}{*}{ a.Work surface } & 14 & 22 & 0 & 20 & Deron & 0 & 3 & 11 & \multirow{2}{*}{0.210} \\
\hline & 14 & 22 & 8 & 28 & веrore & 1 & 5 & 17 & \\
\hline \multirow{2}{*}{ b.Availability of autoclave Sterilization } & \multirow{2}{*}{11} & \multirow{2}{*}{25} & \multirow{2}{*}{8} & \multirow{2}{*}{28} & \multirow{2}{*}{ Before } & 0 & 3 & 8 & \multirow{2}{*}{0.581} \\
\hline & & & & & & 1 & 5 & 20 & \\
\hline \multirow{2}{*}{ c.Availability of adequate amount of disinfection agents } & \multirow{2}{*}{13} & \multirow{2}{*}{23} & \multirow{2}{*}{7} & 29 & \multirow{2}{*}{ Before } & 0 & 3 & 10 & \multirow{2}{*}{0.180} \\
\hline & & & & 29 & & 1 & 4 & 19 & \\
\hline \multirow{2}{*}{$\begin{array}{l}\text { d.Availability of guidelines protocols, circulars in relation to } \\
\text { Sterilization and disinfection }\end{array}$} & \multirow{2}{*}{19} & \multirow{2}{*}{17} & \multirow{2}{*}{$\begin{array}{l}1 \\
1\end{array}$} & 25 & \multirow{2}{*}{ Before } & 0 & 6 & 13 & \multirow{2}{*}{0.096} \\
\hline & & & & 25 & & 1 & 5 & 12 & \\
\hline \multirow{2}{*}{ e.Supervision of sterilization process by dentist } & \multirow{2}{*}{13} & \multirow{2}{*}{23} & \multirow{2}{*}{5} & 31 & \multirow{2}{*}{ Before } & 0 & 2 & 11 & \multirow{2}{*}{0.057} \\
\hline & & & & 31 & & 1 & 2 & 20 & \\
\hline
\end{tabular}

Table 12: Frequencies and McNemar's test results of Waste Management Practices

\begin{tabular}{|c|c|c|c|c|c|c|c|c|c|}
\hline \multirow{2}{*}{ Measurements on Waste Management Practices } & \multicolumn{2}{|c|}{ Before } & \multicolumn{2}{|c|}{ After } & \multirow{2}{*}{\multicolumn{2}{|c|}{ Categories }} & \multicolumn{2}{|c|}{ After } & \multirow{2}{*}{ P-value } \\
\hline & 0 & 1 & 0 & 1 & & & 0 & 1 & \\
\hline \multirow{2}{*}{ a.General cleanliness of the dental clinic } & \multirow{2}{*}{7} & \multirow{2}{*}{29} & \multirow{2}{*}{3} & \multirow{2}{*}{33} & \multirow{2}{*}{ Before } & 0 & 1 & 6 & \multirow{2}{*}{0.289} \\
\hline & & & & & & 1 & 2 & 27 & \\
\hline \multirow{2}{*}{$\begin{array}{l}\text { b.Availability of waste segregation/ categorization system } \\
\text { according to colour code }\end{array}$} & \multirow{2}{*}{12} & \multirow{2}{*}{24} & \multirow{2}{*}{6} & \multirow{2}{*}{30} & \multirow{2}{*}{ Before } & 0 & 2 & 10 & \multirow{2}{*}{0.180} \\
\hline & & & & & & 1 & 4 & 20 & \\
\hline \multirow{2}{*}{ c.Availability of sharp bin } & \multirow{2}{*}{3} & \multirow{2}{*}{33} & \multirow{2}{*}{1} & \multirow{2}{*}{35} & \multirow{2}{*}{ Before } & 0 & 0 & 3 & \multirow{2}{*}{0.625} \\
\hline & & & & & & 1 & 1 & 32 & \\
\hline \multirow{2}{*}{$\begin{array}{l}\text { d. Availability of CPD activities in relation to waste management in } \\
\text { periodically }\end{array}$} & \multirow{2}{*}{24} & \multirow{2}{*}{12} & 1 & \multirow{2}{*}{17} & \multirow{2}{*}{ Before } & 0 & 19 & 5 & \multirow{2}{*}{0.063} \\
\hline & & & 9 & & & 1 & 0 & 12 & \\
\hline
\end{tabular}


Although McNemar's test (Table 13) shows statistically insignificant improvement, the availability of emergency medicine tray (8.3\% to $22.22 \%$ ), availability of essential emergency drugs (5.5\% to $13.88 \%$ ), emergency equipment (5.5\% to $13.88 \%)$, and emergency medicine tray checklist ( $0 \%$ to $5.5 \%$ ) was improved after the intervention.

Table 13: Frequencies and McNemar's test results of Assessment of Emergency Medicine Tray

\begin{tabular}{|c|c|c|c|c|c|c|c|c|c|}
\hline \multirow{2}{*}{ Measurements on Assessment of Emergency Medicine Tray } & \multicolumn{2}{|c|}{ Before } & \multicolumn{2}{|c|}{ After } & \multicolumn{2}{|c|}{ Categories } & \multicolumn{2}{|c|}{ After } & \multirow{2}{*}{ P-value } \\
\hline & 0 & 1 & 0 & 1 & & & 0 & 1 & \\
\hline \multirow{2}{*}{ Availability of emergency medicine tray } & \multirow{2}{*}{33} & \multirow{2}{*}{3} & \multirow{2}{*}{28} & \multirow{2}{*}{8} & \multirow{2}{*}{ Before } & 0 & 27 & 6 & \multirow{2}{*}{0.125} \\
\hline & & & & & & 1 & 2 & 1 & \\
\hline \multirow{2}{*}{ Availability of essential emergency drugs } & \multirow{2}{*}{34} & \multirow{2}{*}{2} & \multirow{2}{*}{31} & \multirow{2}{*}{5} & \multirow{2}{*}{ Before } & 0 & 31 & 3 & \multirow{2}{*}{0.250} \\
\hline & & & & & & 1 & 0 & 2 & \\
\hline \multirow{2}{*}{ Availability of essential emergency equipment } & \multirow{2}{*}{34} & \multirow{2}{*}{2} & \multirow{2}{*}{31} & \multirow{2}{*}{5} & \multirow{2}{*}{ Before } & 0 & 31 & 3 & \multirow{2}{*}{0.250} \\
\hline & & & & & & 1 & 0 & 2 & \\
\hline \multirow{2}{*}{ Availability of emergency medicine tray checklist } & \multirow{2}{*}{36} & \multirow{2}{*}{0} & \multirow{2}{*}{34} & \multirow{2}{*}{2} & \multirow{2}{*}{ Before } & 0 & 34 & 2 & \multirow{2}{*}{0.500} \\
\hline & & & & & & 1 & 0 & 0 & \\
\hline
\end{tabular}

The availability of emergency medicine tray plays a significant role in patient safety in dentistry (Haas, 2006). Alhamad et al. (2015) reported that $75 \%$ of the dentists maintained emergency kits in their dental clinics in the Eastern Province of Saudi Arabia. According to the present study, the availability of emergency medicine tray shows $8.3 \%$ to $22.22 \%$ improvement after the intervention although statistically insignificant in this study $(\mathrm{p}=0.125)$.

\section{CONCLUSIONS}

This study provides an insight into the enhancement of safety practices of the oral healthcare system in the RDHS-Badulla District. It shows an improvement of awareness regarding the safety of the dentists, errors, mistakes, adverse events reporting system, availability of dental safety checklist after the intervention. Periodic awareness on patient safety aspects, encouragement to use a safety checklist in the oral health care clinic, motivation to maintain emergency medicine trays in dental clinics, motivation to maintain incidence, accidence, error mistake reporting system in the oral health care clinic and Continuous supervision and clinical audits were recommended to improve the Patient Safety Practices in the Out Patient Department of Oral Health Care Clinics.

\section{ETHICAL IMPLICATIONS}

Ethical clearance for the study was obtained from the Ethical review committee of the Postgraduate Institute of Medicine, University of Colombo 
APPENDIX 01

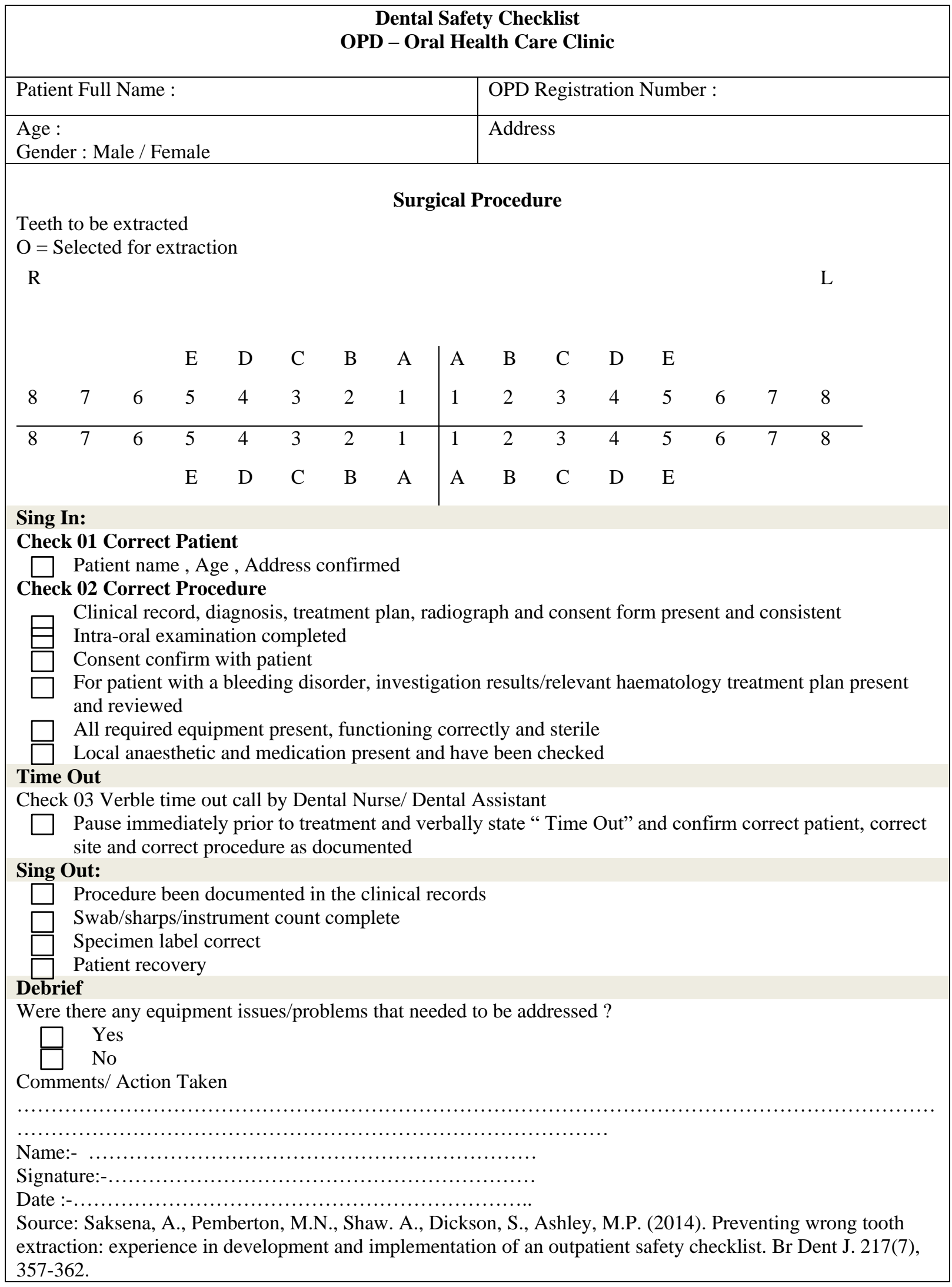




\section{Error, Mistake, Adverse Event, Incident, Accident, Near misses Reporting}

Patient Name:

Age:

Gender: Male/Female

OPD Register Number:

Date :

Time :

Incident Details:

Type of Incident :

Treatment error/Injury/Equipment error/Unsafe working enviroment/Sharp injury/Other

Initial actions taken :

Suggested treatment:

Other recomendation:

Reported by :

Signature : 


\section{REFERENCES}

Amarapathy, M., Sridharan, S., Perera, R., Handa, Y. (2013). Factors Affecting Patient Safety Culture In A Tertiary Care Hospital in Sri Lanka, Int. J. Sci. \& Tech. Resear., 2(3), 173-180.

Al Sweleh, F.S., Al Saedan, A.M., Al Dayel, O.A. (2018). Patient safety culture perceptions in the college of dentistry, Medicine, 97(2), e9570.

Alhamad M., Alnahwi T., Alshayeb H., Alzayer A., Aldawood O., Almarzouq A,, Nazir M.A. (2015). Medical emergencies encountered in dental clinics: A study from the Eastern Province of Saudi Arabia, J. Family Community Med., 22(3), $175-179$.

Arriaga, A.F., Bader, A.M., Wong, J.M., Lipsitz, S.R., Berry, W.R., Ziewacz, J.E., Hepner, D.L., Boorman, D.J., Pozner, C.N., Smink, D.S., Gawande, A.A. (2013). A simulation-based trial of surgical-crisis checklists, N. Engl. J. Med., 368, 1459-1460.

Bailey, E., Tickle, M., Campbell, S., Lucy, O. (2015). Systematic review of patient safety interventions in dentistry, BMC Oral Health, $15,152-163$

Beddis, H.P., Davies, S.J., Budenberg, A., Horner, K., Pemberton, M.N. (2014). Temporomandibular disorders, trismus and malignancy: development of a checklist to improve patient safety, Br Dent J., 217(7), 351-355.

Haas, D.A. (2006). Management of medical emergencies in the dental office: conditions in each country, the extent of treatment by the dentist. Anesth Prog., 53(1), pp. 20-24.

Issadeen, S.R. and Issadeen, A. (2019). Factors Affecting Patient Safety Culture in Selected Base Hospitals in the Regional Director of Health Services Division Kalmunai- Sri Lanka. IOSR Journal of Dental and Medical Sciences, 18(10), 22-27.

Jadhav, A., Kumar, S., Acharya, S., Bhalinge, P., Ganta, S. (2016). Patient Safety practices in dentistry: A Review. International Journal of Scientific Study. 3(10). pp. 163-165.

Jonsson, L. \& Gabre P. (2014). Adverse events in public dental service in a Swedish county-a survey of reported cases over two years. Swed Dent J., 38(3), 151-160.

Kohn, L.T., Corrigan, J. M., Donaldson, M.S. (Eds.). (2000). To Err is Human: Building a Safer Health System. Institute of Medicine (US) Committee on Quality of Health Care in America National Academies Press (US).

Liyanagamage, H.D.D.C. \& Saranasinghe, D.R.N. (2017). Factors affecting patient safety culture in Sri Lankan hospitals. Management Issue, 2(I), 43-52.

Mahar, P., Wasiak, J., Batty, L., Fowler, S., Cleland, H., Gruen, R.L. (2012). Interventions for reducing wrong-site surgery and invasive procedures. Cochrane Database Syst Rev (9), CD009404.

Mettes, T., Bruers, J., van dar Sanden, W., Wensing, M. (2013). Patient safety in dental care: A challenging quality issue? An exploratory cohort study. Acta Odontologica Scandinavica, 71, 1588-1593.

Ministry of Healthcare and Nutrition (2018) Annual Health Statistics (2016) Colombo. Sri Lanka 2018.

Ministry of Health, Sri Lanka, .National Guidelines for Improvement of Quality and Safety of Healthcare Institutions (2010,a). Jayantha, W., Sridharan, S., Aluthweera C.J. Kanamori, S.. (Eds.).Quality Series No.1. (For Line Ministry and Provincial Hospitals) ${ }^{\text {st }}$ Edn. September 2010.

Ministry of Health, Sri Lanka (2010,b). National Guidelines for Improvement of Quality and Safety of Healthcare Institutions Jayantha, W., Sridharan, S., Aluthweera C.J. Kanamori, S.. (Eds.). Quality Series No. 2. (For primary medical health care unit). $1^{\text {st }}$ Edn. September 2010 .

National Oral Health Survey Sri Lanka 2015-2016. Colombo: Ministry of Health, Nutrition and Indigenous Medicine (Sri Lanka); 2018.

Obadan, E.M., Ramoni, R.B., Kalenderian, E. (2015). Lessons learned from dental patient safety case reports. $J$ Am Dent Assoc., 146(5), 318-326. 
Perea-Pérez, B., Santiago-Sáez A., García-Marín, F., Labajo-González, E. (2011). Proposal for a "surgical checklist" for ambulatory oral surgery. Int J Oral Maxillofac Surg., 40. 949-954.

Perea-Pérez, B., Labajo-González, E.,' Santiago-Sáez, A., Albarrán-Juan, E., Villa-Vigil, A. (2014). Analysis of 415 adverse events in dental practice in Spain from 2000 to 2010. Med Oral Patol Oral Cir Bucal., 19(5), e500-e505.

Pemberton, M.N. (2014). Developing patient safety in dentistry. British Dental Journal, 217(7), 335-337.

Saksena, A., Pemberton, M.N., Shaw. A., Dickson, S., Ashley, M.P. (2014). Preventing wrong tooth extraction: experience in development and implementation of an outpatient safety checklist. Br Dent J. 217(7), 357-362.

Sorra J, Gray L, Streagle S, et al., (2018). AHRQ Hospital Survey on Patient Safety Culture: User's Guide. (Prepared by Westat, under Contract No. HHSA290201300003C). AHRQ Publication No. 18-0036-EF (Replaces 04-0041, 15(16)-0049-EF). Rockville, MD: Agency for Healthcare Research and Quality. July 2018.

https://www.ahrq.gov/sops/qualitypatientsafety/patientsafetyculture/hospital/index.html

Sridharan, S., Refai, M.A.C.M., Anwar, N., Kumari, M.K. (2017). Factors affecting patient safety programme in government hospitals of Sri Lanka. Science Journal of Public Health, 5(3), pp. 224-229.

Yamalik, N. \& Perea-Pe'rez B.P. (2012). Patient safety and dentistry: what do we need to know? Fundamentals of patient safety, the safety culture and implementation of patient safety measures in dental practice. International Dental Journal 62, pp. 189 -196.

\section{AUTHORS}

First Author - Y.M.S.S. Yapa, MD, Postgraduate Institute of Medicine, University of Colombo, ymssyapa@ gmail.com

Second Author - S.N. Kumari, PhD, Department of Science and Technology, Faculty of Applied Sciences, Uva Wellassa University, Badulla, Sri Lanka (if any) and email address, sandya@uwu.ac.lk

Third Author - S.R. Jayasinghe, BSc, Department of Science and Technology, Faculty of Applied Sciences, Uva Wellassa University, Badulla, Sri Lank, shani91jaya@yahoo.com

Fourth Author - T.H.N.G. Amaraweera, PhD, Department of Applied Earth Sciences, Faculty of Applied Sciences, Uva Wellassa University, Badulla, Sri Lanka, gayani@uwu.ac.lk 